\title{
Hedonic Approaches to Estimating the Impacts of Open Spaces: A Case Study in the Cape
}

\author{
Hugo van Zyl \\ Independent Economic Researchers cc, Cape Town
}

Anthony Leiman

School of Economics, University of Cape Town

\begin{abstract}
Preliminary desktop studies have been carried out to illustrate the potential value of metropolitan open space areas in Durban and Cape Town using speculative estimates derived mainly from values in the intemational literature. This paper investigates the effects that a selected open space (Zandvlei in Muizenberg) has on nearby property values and attaches values to the space using a combination of estate agent interviews and statistical analysis (hedonic pricing). The results indicate that using statistical analysis generates reasonably similar valuation estimates when compared to the use of estate agent interviews. The property price premiums or discounts associated with open spaces are found to be case specific, but certain trends are discernable that should apply to all areas. Finally, the strengths and weaknesses of the property price approach are discussed.
\end{abstract}

JEL Q00, Q26

\section{INTRODUCTION}

Recently, two studies into the metropolitan open spaces of Cape Town (Common Ground, 2000) and Durban (Markowicz et al., 1999) extrapolated estimates from the international literature to obtain preliminary values of open spaces. These studies alerted city personnel to the services provided by open space areas, and to the use of environmental valuation tools in assessment and management decision-making. The result was a more detailed investigation of Cape Town's open spaces, one part of which (their effects on property values) is detailed in this paper.'

Hedonic theory presumes that property prices capture not only the physical characteristics of houses and properties, but also environmental and social characteristics such as proximity to open space, views and security. This link allows the valuation of these environmental characteristics. This paper uses 
hedonic theory to investigate the effects of open spaces on nearby property values in a selected part of Cape Town (the residential areas surrounding Zandvlei in Muizenberg). The approach differs from the norm in using both a characteristics approach, based on estate agent interviews, and a more conventional statistical technique. The applicability of the valuation results to other similar areas in Cape Town is also briefly discussed.

\section{METHODOLOGY}

\section{Methodological approach}

Basic hedonic valuation begins with a regression. The price of property being a function of its characteristics, one regresses a vector of property prices against the corresponding vectors of those properties' characteristics. The coefficients of the independent variables provide partial derivatives. If one of these parameters is 'distance from open space', then its coefficient is a marginal value. Note, however, that this is not the value of an incremental square metre of open space, but rather the disamenity of moving an incremental distance further from that space. Once one has an idea of the limits to this effect one can measure the impacts of open spaces on surrounding property prices. A priori, the further a house is from the open space, the less the influence of that space on the property's price.

Finding an appropriate form for the regression was an initial concern. Estate agent interviews suggested that the impact of an open space on property prices would fall to zero within four rows of housing from the space itself. This opened a number of paths. For example, the reciprocal of the distance from the open area could be used as the relevant independent variable. This sounds reasonable, but the resulting asymptotic decline (if one assumes that open space generates a price premium) as one moves away does not accord with estate agents' opinions. An intuitive response might be to use dummies: using the suggestion that impacts are exhausted once the fourth row of houses from the open space has been reached, simply ascribe a row number to each property. Those facing the vacant land would be ascribed a value 3 , those in the second row a value 2 , in the third row a value 1 , and all others a value of 0 . However, the choice of dummy values is arbitrary, and the physical distance of the second and subsequent rows of houses from the edge of an open space will be affected by the widths of the intervening stands. Stand sizes clearly vary as one moves from high-income to low-income suburbs. Given these constraints and the opinions of estate agents, a simpler dummy variable approach (borders open space/doesn't border open space) was used, in combination with a simple distance scale, in which the premium or discount in the prices of intervening 
houses was the difference between their actual sale price and the calculated sale price if the house had been located in the sixth row from the open space.

It needs to be stressed that the hedonic discount (or premium) is not a welfare measure, merely an indicator of impacts on market prices. The premium can, however, be used as a welfare measure within any area with homogeneous residents. This was recognised in the seminal literature on hedonic pricing: "If buyers are identical, but sellers differ... single cross-sectional observations trace out compensated demand functions" (Rosen, 1974: 51). This requires the strong assumptions that both incomes and utility functions are identical over all households in the data set. Failing these, one should proceed to one of the second steps recommended by Rosen himself, by Nelson (1978) and Freeman $(1979,1994)^{2}$. In this study, the impacts of open spaces were localised and generally fell in areas with relatively homogeneous communities. While this justified the use of a one step approach, it meant the use of multiple and relatively small data sets.

The majority of published hedonic pricing applications have used a two-step approach with large (city wide) data sets into which all available variables have been inserted. There is merit in following this approach, but it requires a high level, often heroic, aggregation across suburbs and unique areas within suburbs. This aggregation increases the risk of misinterpreting local realities. In this paper we have used a different approach. Our basic premise is that a set of micro-samples (of at least forty or fifty sales figures properly de-trended), taken on a suburb by suburb basis, can be more useful when analysing local effects, provided it is informed by extensive estate agent interviews. These interviews would have to be conducted using the same 'hedonic'- or 'characteristics'-based approach that underpins the statistical technique. Where there is insufficient local sales data for statistical analysis, carefully structured interviews with estate agents can still offer useful information on values.

The study therefore comprises a series of independent regressions, each using data from areas with a homogeneous population. The results are expressed in monetary terms, but since the marginal utility of money varies between the affluent and the poorer suburbs, the results do not allow comparisons of utility between suburbs or even aggregation of the figures to give a total utility equivalent. ${ }^{3}$ The approach used only allowed estimation of the relative (i.e. localised) effects of open spaces on properties in close proximity to them. It did not capture the full influence of open spaces on property prices at a larger (city wide) scale. Thus it could not answer the question, 'does Cape Town property command a premium over that elsewhere in South Africa because of Cape Town's open spaces?' It also does not capture inter-suburb variations in value. To have done so, comparisons between suburbs similar in all respects apart 
from the amount of open spaces would have been necessary. Apart from time and budget constraints, the potential pitfalls of such an approach, in particular the development of indices of open space quantity and quality, were prohibitive and it was not attempted.

\section{Application}

The open space valuation process commenced with interviews of four estate agents operating in the study area. These provided opinions on the effects of open spaces on property prices, but more importantly helped to identify the key variables driving property prices in specific areas. A previous study using property transaction data in Cape Town (Leiman \& Van Zyl, 1998) had shown that:

- The multiplicity of housing and property variables, together with the generally low number of relevant property transactions in any area, could cause problems through inadequate degrees of freedom.

- House characteristics (number of bed-rooms, servants quarters, number of garages, pool, stand size, roof size etc) often demonstrated significant colinearity. Consequently, with small samples, the explanatory power of any regression could be enhanced by simply using roof area as a proxy for many house related variables, after controlling for double story houses, duplexes and flats.

- Issues such as proximity to schools, noisy roads, and pubs, could be significant local factors. These 'neighbourhood' factors are not generally recorded and are easily overlooked.

It was initially hoped that the agents would have ready-evolved rough 'characteristics-based' valuation formulae, as they have in certain of the city's other suburbs. The variables in these could then be tested and used for further statistical valuation exercises. Unfortunately, few agents in the areas involved took such an approach to the valuation process. Most claimed to base their valuations on experience and intuition. However, asked to explain further, these proved to be merely combinations of previous prices achieved for the house in question, those achieved for houses nearby, and a judgment of the state of the property market. ${ }^{5}$ In discussion what emerged was that an implicit hedonic approach was actually followed. An estate agent's valuation of a property is a function of a vector of characteristics - the property's and the neighbourhood's - and the prices of similar houses in the area, or of the property's own historic sale prices and the relative 'state of the market'. This approach is fairly standard in the literature, though the functional forms used vary widely. ${ }^{6}$ 
Detailed property sales data available from Cape Property Services (CPS) over the four-year period January 1998 to April 2001 were used in the analysis. The CPS records indicate the final selling price, the asking price, and the time taken to sell the property. The first of these was used as a dependent variable after detrending for inflation, but clearly the potential exists for a more sophisticated model that could take cognisance of all three price aspects. Also included are the following, from which independent variables were chosen: house size, stand size, condition of the house, number of garages, numbers and types of rooms (living-, bed- \& bathrooms), and special features, such as roof (thatch, tile, iron), pool, north facing, servants' quarters, etc. This offered another justification for the use of a simplified vector of property characteristics, since a number of these would have had to be dummies whose coefficients would have added little to the analysis. Since each analysis focused on a separate area proximate to a given open space, and no comparisons were intended, neighbourhood variables could be omitted. The distance of each house from the nearest open spaces was measured using maps with erf numbers and street addresses provided by the municipality.

Two study areas were specified by the City of Cape Town as valuation case studies of interest to them: Metro South and Metro South-East. In the former, Zandvlei was chosen for specific analysis as an example of a large open space of ecological as well as recreational importance. Zandvlei also presented the opportunity for an interesting case study, as the areas surrounding it are characterised by a mix of conventional and marina type housing. Finally, it was chosen due to the availability of abundant house sales data.?

\section{VALUATION RESULTS}

\section{The study area}

Zandvlei is a natural vlei used for recreational canoeing, sailing and windsurfing (see Figure 1 below for a map of the area). Its western shores are lawned parkland, equipped in places with barbeque and picnic spots and also a boating clubhouse. It is surrounded by four residential areas: Lakeside/Muizenberg North to the west, Muizenberg to the south, Marina Da Gama to the east, and Sheraton Park and Frogmore Estate to the north. The portion of Lakeside/Muizenberg North between the vlei and the railway line that runs approximately three hundred metres to the west is similar to the portion of Muizenberg that borders on the vlei to the south. Residential housing in both these areas offers easy access to the vlei and, in some cases, a vlei view. Marina $\mathrm{Da}$ Gama on the eastern shores also offers these benefits, but is distinct in having been designed as an enclosed (and therefore secure) marina. Sheraton 
Park, on the other hand, borders on reed beds and is fenced off from the vlei offering neither access nor views.

\section{Figure 1 Zandvlei and surrounding residential areas}

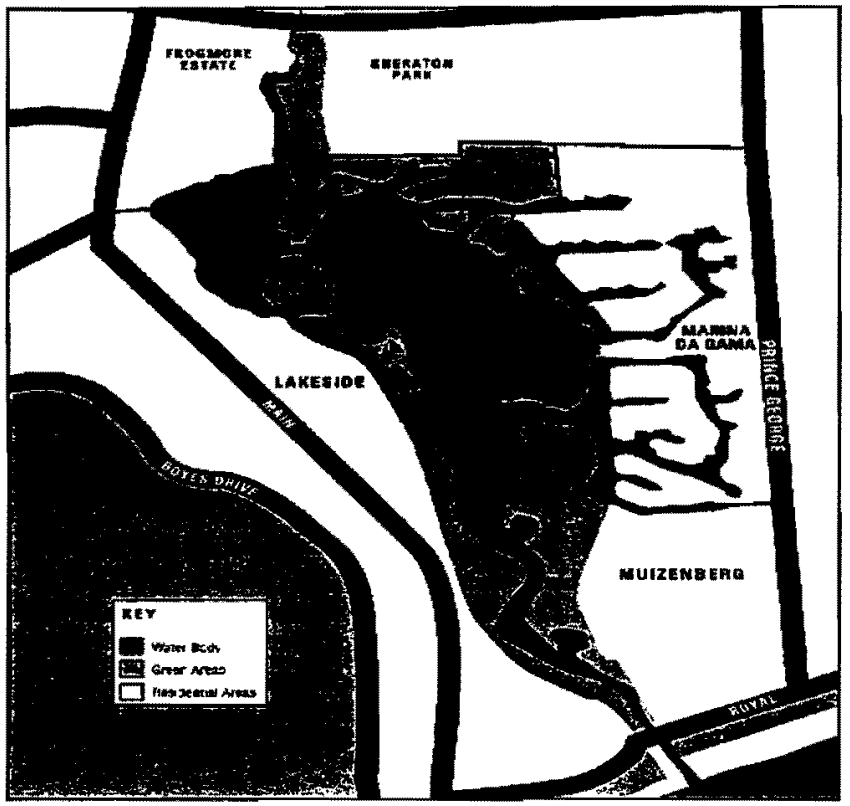

\section{Results of interviews with estate agents}

\section{Lakeside}

Estate agents would only speak confidently about the influence of the vlei on property values in the portion of Lakeside between the vlei and the railway line running next to Main Road. For this area, it was felt that proximity to the vlei yielded a positive premium. The premium for the first row of houses facing onto the landscaped areas on the vlei's shores was estimated at between 7 per cent and 12 per cent. This premium captured the view and sense of open space as well as recreational access. The interviewees provided insights that conventional hedonic studies would have missed. In particular, they argued that the premium would not be constant along the first row of housing. Some agents felt that the houses south of the yacht club overlooking the barbeque facilities enjoyed no premium and might even sell at a discount due to the disturbance in this area over weekends. In this case, some recreational uses of the vlei by day trippers clash with values that could be derived by residents. From the second 
row back towards the railway line, for approximately five rows of houses, recreational access was estimated to add no more than 3 per cent to values. Beyond that point, estate agents doubted any premium. This implies that the view and sense of open space, enjoyed by those whose properties actually face onto the water, add a 4 per cent to 9 per cent premium.

The area between Main Road and Boyes Drive not only offers relatively easy access to the vlei, but also a view of the vlei that should add value. However, it is also on the slopes of Muizenberg Mountain. Extensive interviewing of residents would be required to separate the value specifically added by the view of the vlei from that added by the view in general and by proximity to the mountain.

Estate agents described security as one of the most important considerations for buyers. An example used was the difficulty of selling houses near the unlandscaped northern section of the vlei, an area of dense reed-beds. Potential buyers were deterred by a belief that criminals could gain easy access via the vlei. By contrast, houses facing Westlake golf course (which is fenced and offers no access to residents) command higher prices than similar houses close by, which border on unmanaged open space (to which they do have access). The golf course, to which access is strictly controlled, is seen to lower residents' security risks while the nearby open space is seen to raise them.

\section{Muizenberg}

Muizenberg borders on the southern and south-eastem parts of the vlei. Interviews with estate agents suggested that the vlei's effects on property prices would be similar to those at Lakeside (i.e. 7 per cent to 12 per cent premia in the row of houses bordering the vlei and 3 per cent premia for those in the second to the fifth rows from it). This is not surprising as the landscaped park areas of the vlei offer similar views and recreational opportunities to residents of these two areas.

\section{Marina Da Gama}

The Marina Da Gama complex was designed with Zandvlei (and the views and recreational options associated with water frontage) as its main selling point. Consequently position in relation to the water is a primary determinant of prices. Estate agents argued that having water-frontage was key, A house without water-frontage would lose value markedly, and it would make little difference if it was two rows or five rows from the water. An average house in the marina without water frontage or views sells, at the time of this study, for approximately R400 000. Interviewees argued that the same house with water frontage and south-facing would sell for approximately R500 000 (a 25 per cent 
premium). The price would rise to R600 000 if the house were north-facing (a premium of 50 per cent).

Most of the abovementioned south- and north-facing houses have a view over an arm of water onto the houses on the opposite side of the channel. The largest premia are achieved by the few houses that face westward and have uninterrupted views over the vlei. Within this group are two subsets. The first are the prime properties in the marina looking out over Park Island - an attractive island that is covered in well-maintained indigenous vegetation, has good bird life and only offers low-key recreation in the form of walking trails. Estimating premia for these houses is difficult as they are the largest in the marina and there are no similar houses for comparison. Premia for this group are, however, likely to exceed the 50 per cent achieved by the north-facing houses. The second group offers a less attractive view over the peninsula in the south of the vlei, which is a grassed public park area used for high intensity recreation and picnics. Not only is the view less attractive, there is less privacy and there is a possibility of disturbance by recreational users. Estimating premia for these houses is also difficult as some of the negative influences on house prices have been recently mitigated; there is as yet no indication of how the market will adjust. Positive improvements include stricter control for recreational access, only allowing access before seven in the evening, and limiting noise levels. Premia for this subset are estimated at between 25 per cent and 50 per cent.

\section{Sheraton Park and Frogmore Estate}

Sheraton Park and Frogmore estate border on reed beds and are fenced off from the northem part of the vlei, offering neither access nor views. Estate agents felt that proximity to the vlei did not add to property values and, due to security concerns, could even detract from them. The extension of Steenberg Road along the northern boundary of the vlei to link up with Prince George Drive has been mooted for many years. This has curtailed expenditure on management measures to upgrade the open space (as it has been earmarked for potential road works), further discouraging buyers. Separating out these expectations-based effects again proved difficult.

The information from estate agents outlined above was used to estimate following premia for each area: 
Table 1 Property price premia associated with proximity to Zandvlei generated using estate agent interviews

\begin{tabular}{|c|c|c|c|c|}
\hline & Lakeside & Muizenberg & $\begin{array}{c}\text { Marina Da } \\
\text { Gama }\end{array}$ & \begin{tabular}{|c|}
$\begin{array}{c}\text { Zandvlei all } \\
\text { areas }\end{array}$ \\
\end{tabular} \\
\hline Average house price & R300 000 & R300000 & $\mathrm{R} 400000$ & \\
\hline \multicolumn{5}{|c|}{ Row of houses away from open space } \\
\hline $\begin{array}{l}\text { Premium as percentage of } \\
\text { average house price }\end{array}$ & $9.50 \%$ & $9.50 \%$ & $37.50 \%$ & \\
\hline Premium per house & R28 500 & $\mathrm{R} 28500$ & R150000 & \\
\hline Number of houses affected & 28 & 65 & 583 & 676 \\
\hline \multirow[t]{2}{*}{ Total premium } & R399000 & R1 852500 & $\mathrm{R} 87450000$ & R89 701500 \\
\hline & & & & i. \\
\hline \multicolumn{5}{|c|}{ Second row of houses away from open space } \\
\hline $\begin{array}{l}\text { Premium as percentage of } \\
\text { average house price }\end{array}$ & $2.25 \%$ & $2.25 \%$ & $0 \%$ & \\
\hline Premium per house & R6 750 & R6 750 & 0 & \\
\hline Number of houses affected & 26 & 65 & 198 & 289 \\
\hline Total premium & R175 500 & R438750 & 0 & R614 250 \\
\hline \multicolumn{5}{|c|}{ Third row of houses away from open space } \\
\hline $\begin{array}{l}\text { Premium as percentage of } \\
\text { average house price }\end{array}$ & $2.25 \%$ & $2.25 \%$ & $0 \%$ & \\
\hline Premium per house & RR6 750 & R6750 & 0 & \\
\hline Number of houses affected & 26 & 57 & 61 & $\overline{144}$ \\
\hline Total premium & R148 500 & $\mathrm{R} 384750$ & 0 & R560 250 \\
\hline \multicolumn{5}{|c|}{ Fourth row of houses away from open space } \\
\hline $\begin{array}{l}\text { Premium as percentage of } \\
\text { average house price }\end{array}$ & $2.25 \%$ & $2.25 \%$ & $0 \%$ & \\
\hline Premium per house & R6750 & R6 750 & 0 & \\
\hline Number of houses affected & 22 & 50 & 51 & 123 \\
\hline Total premium & R148 500 & R337 500 & 0 & R486 000 \\
\hline \multicolumn{5}{|c|}{ Fifth row of houses away from open space } \\
\hline $\begin{array}{l}\text { Premium as percentage of } \\
\text { average house price }\end{array}$ & $2.25 \%$ & $2.25 \%$ & $0 \%$ & \\
\hline Premium per house & R6750 & R6750 & 0 & \\
\hline Number of houses affected & 22 & 45 & 30 & 97 \\
\hline Total premium & R148 500 & R303750 & 0 & $\mathrm{R} 452250$ \\
\hline
\end{tabular}


Table 1 continued

\begin{tabular}{|l|c|c|c|c|}
\hline & Lakeside & Muizenberg & $\begin{array}{c}\text { Marina Da } \\
\text { Gama }\end{array}$ & $\begin{array}{c}\text { Zandvlei all } \\
\text { areas }\end{array}$ \\
\hline All rows of houses & & & & \\
\hline Number of houses affected & 124 & 282 & 923 & 1329 \\
\hline Total premium & R1 047000 & R3 317 250 & R87 450 000 & R91 814250 \\
\hline
\end{tabular}

Assumptions:

- Average premia were used based on estate agent estimates.

- Roughly half of the houses bordering on the vlei in Lakeside have no premium due to the disturbances associated with picnicking, particularly south of the yacht club. The total premium for this row has thus been balved to account for this.

\section{Hedonic analysis}

House sales data for the last four years were collected, de-trended and then analysed for the hedonic model using STATISTICA. Fortunately the vlei had not undergone any major changes in the past four years. An analysis that uses a small sample and many variables can easily run into 'degrees of freedom' problems. Fortunately, we could eliminate conventional hedonic issues like proximity to shops and major roads, pollution sources, etc. as inapplicable to the sample. This left only house characteristics and proximity to open space driving differences in property prices.

Preliminary linear regressions were performed for each of the three areas surrounding the vlei to determine whether statistically significant relationships existed between distance from open space, house characteristics and house price. Significant relationships were found for Marina Da Gama, but not for Muizenberg and Lakeside. Proximity to open space was rejected as a candidate independent variable for Muizenberg and Lakeside when forward step-wise regression was performed (using a standard alpha of .05). This was not unexpected considering the small samples sizes ( 16 for Muizenberg and 14 for Lakeside) coupled with the relatively low expected premium based on estate agent interviews. The data for Muizenberg and Lakeside were excluded from further analysis.

A step-wise regression was then performed on the Marina Da Gama data $(\mathrm{n}=$ 80 ) in order to ensure only statistically significant independent variables were included. Using a dummy to indicate whether a house had water frontage generated results with only marginally better explanatory power than using distance away from the vlei in metres (Adjusted $R^{2}=0.66$ vs. Adjusted $R^{2}=$ 0.63 ). The choice of the dummy approach was informed by this result and the 
fact that it conformed better to the views expressed by estate agents. The results of the regressions were as follows:

Table 2 Zandvlei property price hedonic regression results

\begin{tabular}{|c|c|c|c|c|}
\hline \multirow{2}{*}{$\begin{array}{c}R=.82511486, \\
F(4,76)=40.527,\end{array}$} & $R^{2}=.68081453$ & \multicolumn{3}{|c|}{ ADJUSTED $R^{2}=.66401529$} \\
\hline & Std. En & of estimat & $1474 \mathrm{E} 2$ & \\
\hline Variable & $\begin{array}{l}\text { Estimated } \\
\text { coefficient }\end{array}$ & $\begin{array}{l}\text { Standard } \\
\text { error of } \\
\text { coefficient }\end{array}$ & $\begin{array}{c}\text { Student t } \\
\text { (76 DF) }\end{array}$ & P-level \\
\hline $\begin{array}{l}\text { Water frontage dummy }(1 \\
=\text { on waterfront, } 0=\text { not })\end{array}$ & 131578.4 & 35577.3 & 3.698 & .000408 \\
\hline House size in $\mathrm{m}^{2}$ & 1453.7 & 261.4 & 5.562 & .000000 \\
\hline Stand size in $\mathrm{m}^{2}$ & 199.2 & 108.34 & 1.839 & .069879 \\
\hline Number of garages & 58104.3 & 31292.3 & 1.857 & .067212 \\
\hline
\end{tabular}

Excluding stand size and number of garages as independent variables was considered because of their relatively high p-levels (these should ideally remain below 0.05 ). However, they were ultimately included because their p-levels were not significantly above 0.05 and their inclusion did marginally improve the model's explanatory power (Adjusted $\mathrm{R}^{2}=0.664$ vs. Adjusted $\mathrm{R}^{2}=0.629$ ). Including only one of the two variables was also considered, but rejected as they had reasonably low levels of correlation (correlation coefficient $=0.466$ ), and because doing so would have lowered the Adjusted $R^{2}$ (including only stand size resulted in an Adjusted $R^{2}$ of 0.653 while including only number of garages gave an Adjusted $R^{2}$ of 0.654 ).

The results of the statistical analysis in below compare well with those of the estate agent interviews for Marina Da Gama (R76.7 million using statistical analysis vs. R87.5 million using estate agent interviews). There was insufficient data for the statistical analysis of property prices in Muizenberg and Lakeside to reveal a relationship between house price and proximity to open space. There is, however, no reason to believe that this finding poses a challenge to the views of estate agents that a relationship does indeed exist.

Table 3 Property price premia associated with proximity to Zandvlei (hedonic analysis)

\begin{tabular}{|l|c|}
\hline & Marina Da Gama \\
\hline Number of houses affected & 923 in area, 583 with water frontage \\
\hline Premium per house & R131 578 \\
\hline Total premium associated with vlei & R76.7 million \\
\hline
\end{tabular}




\section{APPLICABILITY OF RESULTS TO OTHER AREAS}

As mentioned before, the results for Zandvlei reported here formed part of a broader study on the effects of open spaces on property prices in Cape Town (Turpie et al., 2001). The study focused on a small set of suburbs with significant areas of open space in the form of parks, sports fields, areas of natural vegetation, agricultural fields and vacant lots. Between them, these areas covered a spectrum of household incomes from relative affluence to absolute poverty. The property price premia or discounts associated with open spaces were found to be highly case-specific in the study. For example, a park in Kuils River created a premium while one in Claremont generated a property price discount. Clearly this implies that extrapolation of premia or discounts is inadvisable without site-specific investigations. However, the following trends appeared at Zandvlei and the other areas investigated as part of the broader Cape Town study:

- Most open spaces lead to premia or discounts of less than 10 per cent. However, areas surrounding major environmental attractions such as Zandvlei can attract substantial premia often above 10 per cent or even 20 per cent. This is particularly true of areas that have been purpose-built to make the most of the environment. It is also interesting to note that the areas that showed the highest premia in the broader Cape Town study included water as a major component of the open space.

- Security is a key determinant of property prices. A perception exists that open space allows easier access for criminals unless specific security-linked provisions have been made.

- The value of an open space depends on the quality of its management. "Well-managed" typically means well-manicured, secured, and free of vagrants and other users who generate disamenity to residents.

- The preservation of botanical diversity and indigenous flora is problematic. Trimmed lawns are often preferred to dense growths of fynbos that are seen as increasing fire and security risks.

- Vacant land discounts may be influenced by expectations of future developments and by uncertainty over the strictness with which zoning and building regulations will be enforced. 


\section{CRITICAL APPRAISAL OF METHODS}

- One of the main strengths of the property price approach is that it derives values from actual market transactions and known trends. This gives ease of understanding and credibility in the eyes of the public and policy-makers. However, effective hedonic analysis using property price effects presupposes adequate data about both the property transactions and the households involved. Data can prove inadequate for a number of reasons, most of which were encountered during the course of this study:

- If open space as a whole is to be appraised, independently of individual sites, then details of the purchasing households are needed. In particular, income, race, education, and tribal or language group seem likely to be influential factors. The conventional approach, which only treats income as a key 'indirect' variable, seems inadequate given the complexities of a city such as Cape Town. In reality neither it, nor any of the other 'indirect' variables mentioned, are recorded when property transactions take place. This means one has to work on a zonal basis, relying on local buyer homogeneity.

- In any local area the number of houses traded may be low. This limits conventional hedonic analysis to larger open spaces with large numbers of homes bordering them.

- The formal property market in the suburbs analysed needs to have been sufficiently active to generate the sales data required.

- Sales data for areas where the property market is not well developed tend to be scarce. This is a particular problem in high-density suburbs. Effectively, the implications of open space for low-income black city dwellers are not adequately evaluated.

The method requires fewer assumptions and less complex analysis when analysing localised property price effects. It seems reasonable that a feature of desirable suburbs is that they are well-wooded and have substantial areas of open space. Unfortunately, the property price approach used here is not suited to such broad scale analysis.

Some of the problems mentioned above can be avoided by making use of estate agent interviews. A caveat is needed, however: it soon became clear that some estate agents were more aware than others of issues and factors driving prices and their movements. Care needs to be exercised when interpreting such inputs. 


\section{CONCLUSION}

The key finding of the study was that open space does not have an identifiable external value per se. It generates flows of services and disservices that impact on the welfare of local residents and are captured in local property prices. Indeed the external values captured were in large measure driven by the activities of the city council in maintaining and regulating greenbelt areas, and in establishing clearly-defined, stable, and policed zoning regulations.

The results of the evaluation indicate that property values can be enhanced by well-managed, secure open spaces free of frequent public disturbances. Effectively we found that the value was not so much determined by the open space itself (or its ecological integrity) as by the quality of its management and the public's perception of its role in social issues such as crime. There is no reason to believe that this finding would change for other areas. This was not an anticipated conclusion.

Property price evaluation based on estate agent interviews proved a reasonably fast way of getting information for all types of open space, while data constraints meant that hedonic analysis had to be more selectively applied. As we performed it, hedonic analysis captured only local effects of open spaces on properties proximate to them. It did not capture the full influence of open spaces on property prices at a larger scale, such as at suburb level. Most importantly, it did not reflect the very real possibility that the property premium Cape Town commands over other cities in South Africa may be a consequence of the city's extensive open spaces.

\section{ENDNOTES}

The authors would like to thank The City of Cape Town for funding the research that made this paper possible. Special thanks to the two anonymous reviewers for their valuable comments and suggestions.

1 The aim of the city study (Turpie et al., 2001) was to ascertain the full value of open spaces and the trade-offs between open spaces and other land uses within the CMA.

2 Some texts simply argue for weak separability in the utility function. In this study, weak separability means that one's preference for open space is not affected by the other features of the house one lives in (independence) and are not locally satiated. 
3 We have serious reservations about valuations which purport to aggregate utilities across an entire population. Aggregating monetary values don't pose a problem, mention of utility in this aggregate way does.

4 The following estate agents for their inputs with regard to poperty price effects at Zandvlei: Derek Ross \& partner (Pam Golding), Megan Wells (Relmax), Carol McFarlane (Cape Coastal Properties).

5 Price records over the preceding seven years for the house in question and for nearby properties can be sourced from the South African Property Transfer Guide database.

6 Contrast this with the conventional hedonic approach which uses the same vector of characteristics, but then adds the characteristics of the buyer.

$7 \quad$ For examples of the use of the property price approach to attach values to wetlands such as Zandvlei, see Mahan (1997), Lupi et al. (1991) and Doss \& Taff (1993).

\section{REFERENCES}

1 COMMON GROUND (2000) Value of Open Space Services in the Cape Metropolitan Area, Cape Town: Cape Metropolitan Council.

2 DOSS, C.R, \& TAFF, S.J. (1993) The Relationship of Property Values and Wetland Proximity in Ramsey County, Minnesota, St. Paul, MN: University of Minnesota Department of Agricultural and Applied Economics Report 93-4.

3 FREEMAN, A.M. (1979) The Benefits of Environmental Improvement: Theory and Practice, Baltimore, MD: John Hopkins University Press for Resources for the Future.

4 FREEMAN, A.M. (1994) The Measurement of Environmental and Resource Values: Theory and Methods, Washington: Resources for the Future.

5 LEIMAN, A. \& VAN ZYL, H.W. (1998) Economic Evaluation of Conservation Proposals for the AECI/Somchem Site in Somerset West, Stellenbosch: CSIR Water, Environment and Forestry Technology.

6 LUPI, F., GRAHAM-TOMASI, T. \& TAFF, S.J. (1991) A Hedonic Approach to Urban Wetland Valuation, St. Paul, MN: University of Minnesota Department of Agricultural and Applied Economics Staff Paper P91-8.

7 MAHAN, B.L. (1997) Valuing Urban Wetlands: A Property Pricing Approach. Alexandria, VA: U.S. Army Corps of Engineers, Institute for Water Resources.

8 MARKOWICZ, T., MARTENS, A., MANDER, M., NICOLS, G., CAMPBELL-GILLIES, S. \& COLLINS, S. (1999) Durban Metro Open 
Space System: Framework Plan, Durban: Environment Branch, Durban Metro Council.

9 NELSON, J.P. (1978) "Residential Choice, Hedonic Prices, and the Demand for Urban Air Quality", Journal of Urban Economics, 5(3): 357 68.

10 ROSEN, S. (1974) "Hedonic Prices and Implicit Markets: Product Differentiation in Pure Competition", Joumal of Political Economy, 82(1): 34-55.

11 TURPIE, J.K., JOUBERT, A., VAN ZYL, H.W., HARDING, B. \& LEIMAN, A. (2001) Valuation of Open Space in the Cape Metropolitan Area: A Pilot Study to Demonstrate the Application of Environmental and Resource Economics Methods for the Assessment of Open Space Values, Cape Town: City of Cape Town Environment Directorate. 